\title{
Exocrine Pancreatic Cancer pT4 TNM Finding v6
}

National Cancer Institute

\section{Source}

National Cancer Institute. Exocrine Pancreatic Cancer pT 4 TNM Finding v6. NCI

Thesaurus. Code C60947.

Exocrine pancreatic cancer extending beyond the pancreas, involving the celiac axis or superior mesenteric artery and therefore unresectable. (from AJCC 6th Ed.) 